\title{
Electropolymerizable Conjugated Polymers with High Contrast in Infrared Region
}

\author{
Zhongtao $\mathrm{Li}^{1^{*}}$, Shuiping Liư ${ }^{2}$, Dong Liu ${ }^{1}$ \\ ${ }^{1}$ State Key Laboratory of Heavy Oil Processing, China University of Petroleum, Qingdao, China \\ ${ }^{2}$ Key Laboratory of Science \& Technology of Eco-textiles a Ministry of Education, Jiangnan University, Wuxi, China \\ Email: *liztao@upc.edu.cn
}

Received September 6, 2012; revised October 5, 2012; accepted October 16, 2012

\begin{abstract}
Two conjugated molecules have been designed and synthesized for preparing electrochromic thin film devices on the surface of electrodes through electropolymerization. These devices exhibit good contrast at around $80 \%$ in mid-infrared region and rapid response time, especially EP02 which could be switched between on and off state in around $1 \mathrm{~s}$. The interesting electrochromic properties and easy processable properties open the door to electrochromic applications using large or flexible surfaces such as IR shutters and apertures.
\end{abstract}

Keywords: Electrochromic; Conjugated Polymer; Donor-Acceptor; Electrodeposition

\section{Introduction}

There is a great deal of interest in new electrochromic (EC) materials which exhibit rapid switching time, longterm stability, and high contrast [1]. Over the past few years, electrochromic devices (ECDs) utilizing electroactive conjugated polymers have received increasing attention owing to their fast response time, low fabrication cost and easy functional modifications [2-4]. Conjugated polymers, such as polyanilines, polypyridines, polypyrroles, polythiophenes [5-9], and in particular, poly (3,4ethylenedioxythiophene) (PEDOT) and PEDOT vinylenes have thus far proved most useful [10]. Dietrich et al. have compared the electrochemical and optical properties of PEDOT and poly (3,4-propylene-dioxythiophene) (PProDOT), which exhibit the most promising electrochromic properties because their electronrich nature gives them especially low redox switching potentials [11-14]. Meanwhile, band gap control is an important strategic key in the construction of polymer based EC devices for a specified contrast in certain wavelength. Serials of conjugated polymers, which con- sist with various donoracceptor subunits, have been developed for controlling specific absorbance [15-18].

Advanced materials capable of large, dynamic (swit chable, controllable) variation of infrared (IR) signature have been intensely sought recently for two urgent applications: 1) As infrared camouflage countermeasures against night vision sensors for all armed forces components (land/sea vehicles, aircraft, soldiers) [19]; 2) For

"Corresponding author. optical information technology, to replace bulky, costly mechanical shutter and filter in infrared detection and imaging [20]. While conducting polymers $[21,22]$ have shown some intrinsic variation of mid-to far-IR signature, the practical utilization of this has remained elusive.

In the earlier work, Dan et al. have synthesized and used of a series of conjugated polymers with different functional groups which have enabled further exploration in the relationship between electrochromic properties and chemical structures [23]. These polymers contain ethylenedioxythiophene (EDOT) units, which provide exceptional stability in the oxidation state and combined with a low energy requirement for oxidation. Fluorene and Carbazole are introduced into the polymer chains to improve ECDs' performance through the adjustment of spacing between the polymer chains to facilitate ion injection [24]. The introduction of the acceptor unit benzothiadiazole (BT) and its derivations was used to decrease the lowest unoccupied molecular orbital (LUMO) level and narrow the band gap, thereby extending absorbance to longer wavelengths.

Herein, we prepare electrochromic thin film devices in the solid state, which are fabricated through electropolymerization in solutions from donor-acceptor-donor narrow band gap monomers. Compared with spin-coated samples [23], these electrodeposited products are easy patterned and fabricated to highly scalable, uniform and homogeneous thin films. Most importantly, the devices based on these films can be switched reversibly between the doped and de-doped states with rapid response times and high contrast in IR, which are promising to be prac- 
tically used on fabrication of large and flexible devices.

\section{Experiment Section}

All reagents are purchased from commercial sources and used without further purification, unless otherwise noted. The solvents are distilled and dried using known methods [25]. All reactions are carried in air atmosphere unless otherwise mentioned. The following acceptor and donor blocks were prepared according to literature procedures: 4,7-dibromo-2,1,3-benzothiodiazole (DB-BT), [26] tributyl (2,3-dihydrothieno [3,4-b][1,4] dioxin-5-yl) stannane (EDOT-T), [27] tributyl (1,4-bis [2-(3,4-propylenedioxythienyl)) stannane (ProDOT-T), [28] 4,7-di(2,3-dihydrothieno $[3,4-b][1,4]$ dioxin-5-yl) benzo $[1,2,5]$ thiadiazole (BDT) [29]. ITO/glass electrodes are obtained from Delta Technologies, Ltd., and rinsed successively with distilled water, acetone and isopropanol before use.

Procedures of synthesizing monomer 1 (4,7-bis (3,3diethyl-3,4-dihydro-2H-thieno[3,4-b][1,4] dioxepin-6yl) benzo[c][1,2,5] thiadiazole). The precursor (1.0 mol ratio), $\mathrm{Zn}$ powder (10 mol ratio) are mixed together in 40 $\mathrm{mL}$ acetic acid, and stirred for 2 hours. After the mixture cool to room temperature, the solid is filtered off and filtrate is evaporated in vacuum. The produce can be used directly without further purification. $50 \mathrm{~mL}$ ethanol is added into the solid and followed by tetradecane7,8 -dione. The reaction is continued for 24 hours in room temperature. And then evaporated in vacuum and purified through silica gel chromatographic column. ${ }^{1} \mathrm{H}$ NMR $\left(500 \mathrm{MHz} \mathrm{CDCl}_{3}\right), \delta=7.85(\mathrm{~s}, 2 \mathrm{H}), 6.54(\mathrm{~s}, 2 \mathrm{H}), 4.40(\mathrm{~m}$, $4 \mathrm{H}), 4.20(\mathrm{~m}, 4 \mathrm{H}), 3.10(\mathrm{tr}, 4 \mathrm{H}), 2.03(\mathrm{~m}, 4 \mathrm{H}), 2.08(\mathrm{br}$, $4 \mathrm{H}), 1.53-1.31(\mathrm{~m}, 16 \mathrm{H}), 0.91(\mathrm{tr}, 6 \mathrm{H}) ;{ }^{13} \mathrm{C} \mathrm{NMR}$ $\left(500 \mathrm{MHz} \mathrm{CDCl}_{3}\right), \delta=152.7,149.8,147.9,127.6,124.3$,
117.4, 106.2, 43.8, 23.7, 7.3; Anal. Calcd for $\mathrm{C}_{32} \mathrm{H}_{38} \mathrm{~N}_{2} \mathrm{O}_{4} \mathrm{~S}_{2}$ : C, 66.41; H, 6.62. Found: C, 66.67, H, 6.32. MS m/z Calcd for $\mathrm{C}_{32} \mathrm{H}_{38} \mathrm{~N}_{2} \mathrm{O}_{3} \mathrm{~S}_{2}$ : 578.8, Found 578.9

Procedures of synthesizing monomer 2 (5,8-bis(2,3dihydrothieno[3,4-b][1,4] dioxin-5-yl)-2,3-dihexy-lquinoxaline). The dibromo monomer (1.0 mol ratio), bis( 4,4 , 5,5-tetramethyl-1,3,2-dioxaborolane) (2.5 mol ratio), $\mathrm{Pd}\left(\mathrm{PPh}_{3}\right)_{4}(0.02 \mathrm{~mol}$ ratio), and toluene were placed into a two neck bottle under argon. After complete dissolution of the reagents, a degassed $2 \mathrm{M} \mathrm{K}_{2} \mathrm{CO}_{3}$ solution was added under argon to the mixture. The reaction was refluxed under stirring for $24 \mathrm{~h}$. The mixture was poured into methanol $(200 \mathrm{~mL})$, and purified through silica gel chromatographic column. ${ }^{1} \mathrm{H}$ NMR $\left(500 \mathrm{MHz} \mathrm{CDCl}_{3}\right), \delta=8.58$ $(\mathrm{s}, 2 \mathrm{H}), 6.54(\mathrm{~s}, 2 \mathrm{H}), 4.40(\mathrm{~s}, 4 \mathrm{H}), 4.32(\mathrm{~s}, 4 \mathrm{H}), 3.10(\mathrm{t}$, 4H), $2.04(\mathrm{~m}, 4 \mathrm{H}), 1.60-1.34(\mathrm{~m}, 12 \mathrm{H}), 0.91$ (tr, 6H); ${ }^{13} \mathrm{C}$ NMR (500MHz $\mathrm{CDCl}_{3}$ ), $\delta=154.4,141.3,140.0$, 137.2, 128.3, 127.1, 113.6, 102.8, 64.9, 64.4, 34.8, 31.9, 29.6, 29.3, 28.3, 22.7, 14.1; (Anal. Calcd for

$\mathrm{C}_{36} \mathrm{H}_{48} \mathrm{~N}_{2} \mathrm{O}_{4} \mathrm{~S}_{3}$ : C, 64.64; H, 7.23. Found: C, 64.36, H, 7.58. MS $m / z$ Calcd for $\mathrm{C}_{36} \mathrm{H}_{48} \mathrm{~N}_{2} \mathrm{O}_{4} \mathrm{~S}_{3}$ : 668.9, Found 669.0 .

\section{Result and Discussion}

\subsection{Electrochemical Polymerization}

Electrochemical studies were carried out with a CHI 600D electrochemical workstation, using an indium tin oxide (ITO)-coated glass slide as the working electrode $\left(25 \times 15 \times 0.8 \mathrm{~mm}, R_{\mathrm{S}}=70-100 \Omega\right)$, a gold flag as the counter electrode, and an $\mathrm{AgCl}$ coated $\mathrm{Ag}$ wire, which was directly dipped in the electrolyte solution, as the reference electrode. The $E_{1 / 2}=\left(E_{\mathrm{pa}}+E_{\mathrm{pc}}\right) / 2$ of the

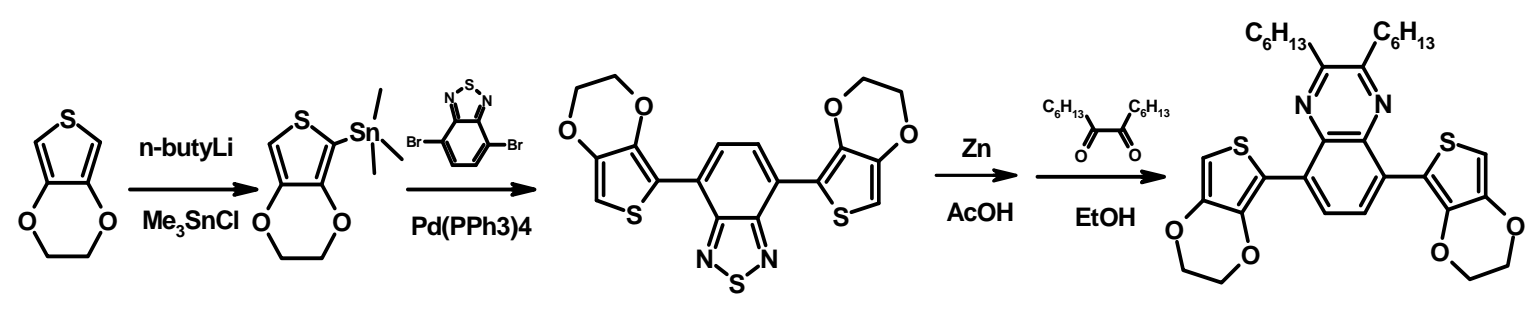

01
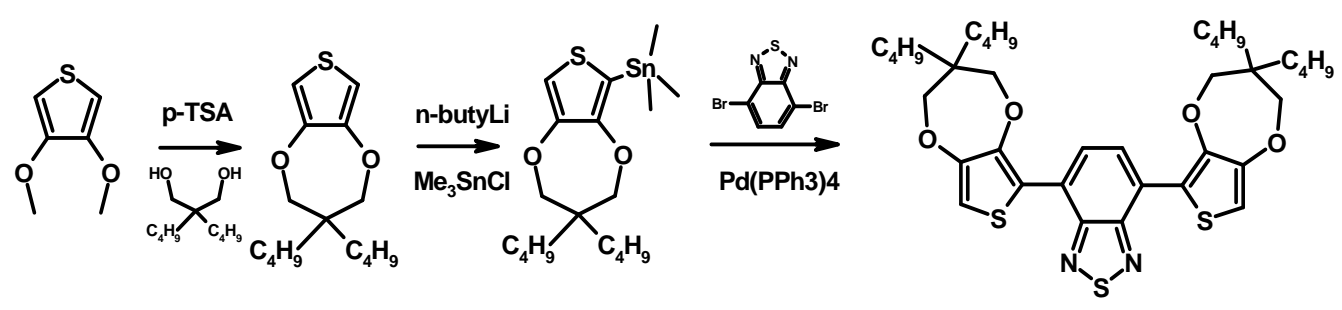

02

Scheme 1. The synthesis protocol of monomer 1 and 2. 
$\mathrm{Fc} / \mathrm{Fc}^{+}$couple is $0.26 \mathrm{~V}$ vs $\mathrm{Ag} / \mathrm{AgCl}$ under these conditions.

The polymer films of EP01 and EP02 (polymerized from monomer 1 and 2, respectively) are deposited on ITO-coated glass substrates by cycled scanning at a scan rate of $250 \mathrm{mV} / \mathrm{s}$ from -0.2 to $1.2 \mathrm{~V} \mathrm{vs} \mathrm{Ag} / \mathrm{Ag}^{+}$from a $0.01 \mathrm{M}$ monomer solution in $0.1 \mathrm{M} \mathrm{TBAPF}_{6} /$ acetonitrile, which are bubbled with nitrogen before use to remove any incipient oxygen. Several drops of Dichloromethane are required to dissolve the monomers and then $\mathrm{CH}_{3} \mathrm{CN}$ is added to get the solution in certain concentration. However, too much $\mathrm{CH}_{2} \mathrm{Cl}_{2}$ hindered polymer formation and deposition on the electrode and only the use of monomer saturated solution helped to circumvent that problem.

The repeated scanning electropolymerizations of monomer 1 and of 2 are shown in Figure 1, respectively. During the first anodic scan, a single peak is observed which corresponds to irreversible monomer oxidation and formation of cation radicals. The oxidation of monomer $1\left(E_{\mathrm{p}, \mathrm{m}}\right)$ is starting at $+1.06 \mathrm{~V}$, and at $1.02 \mathrm{~V}$ for

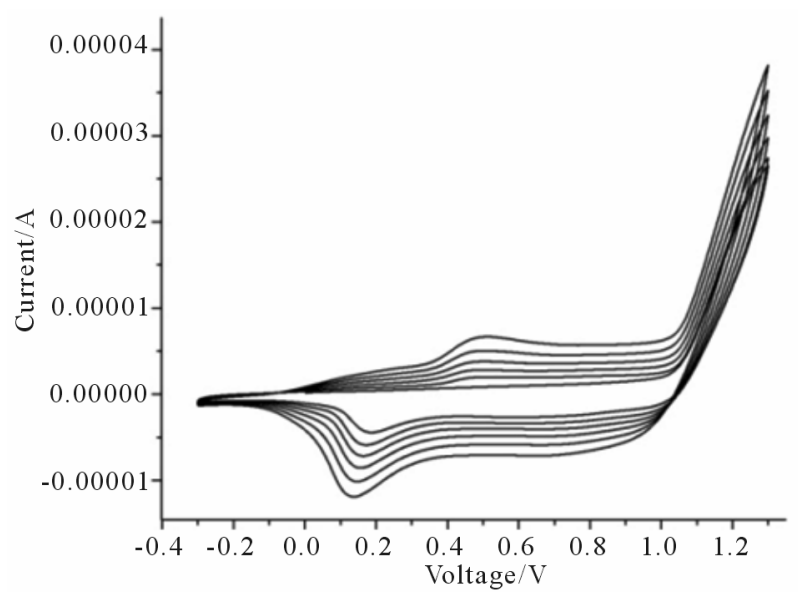

(a)

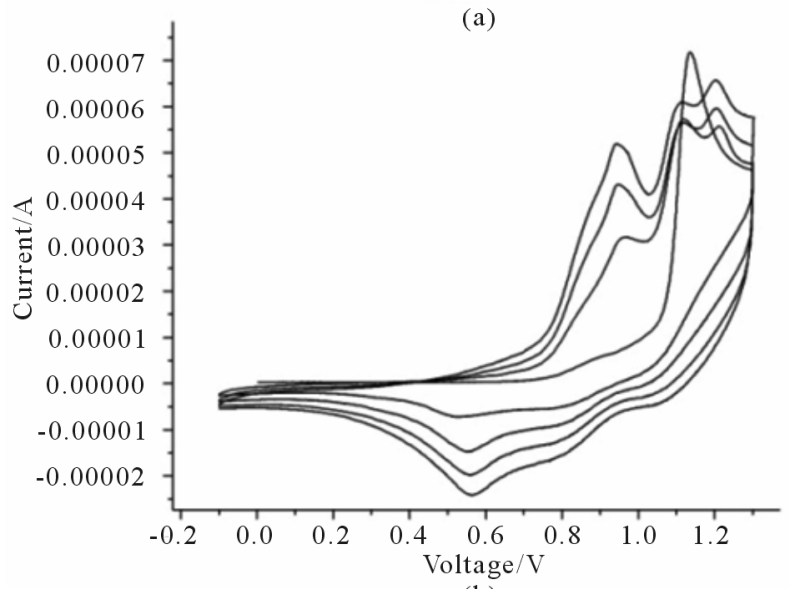

(b)

Figure 1. Cyclic voltammograms of (a) monomer 1 and (b) monomer 2 in $0.01 \mathrm{M}$ monomer solution in $0.1 \mathrm{M} \mathrm{TBAPF}_{6}$ / acetonitrile at scan rates of $250 \mathrm{mV} / \mathrm{s}$. monomer 2. With repeated potential scanning, polymers EP01 and EP02 films grow onto the electrode surface in succession. The oxidation potentials of the polymer also increase with film thickness due to the increase in polymer resistance.

The polymer films formed on the electrode are rinsed with a monomer-free solution of $\mathrm{CH}_{3} \mathrm{CN}$ in which films are not soluble, and cyclic voltammograms are further recorded with scan rate values of $250 \mathrm{mV} / \mathrm{s}$. The $E_{\mathrm{p}, \mathrm{ox}}$ and $E$ p, red of the EP01 and EP02 system are highly separated as the longer and bulkier chains on the periphery inhibit the fast movement of counter ions. The peak oxidation $\left(E_{\mathrm{p}, \mathrm{ox}}\right)$ potentials of EP01 is around $+0.41 \mathrm{~V}$ at 250 $\mathrm{mV} \cdot \mathrm{s}^{-1}$. However, $E_{\mathrm{p}, \text { ox }}$ for EP02 is $+0.75 \mathrm{~V}$ at 250 $\left.\mathrm{mV} \cdot \mathrm{s}^{-1}\right)$. The lower $\left(E_{\mathrm{p}, \mathrm{ox}}\right)$ potentials of EP01 than that of EP02 reveals the weaker effect of the electron accepting capability of the benzo [c] $[1,2,5]$ thiadiazole unit on the polymer oxidation process than that of quinoxaline [30].

\subsection{Optoelectrochemical Analyses}

For assembling electrochromic cells, a quasisolid or viscous gel electrolyte base prepare from an acetonitrile solution of poly(methyl methacrylate) (PMMA), propylene carbonate and ethylene carbonate in weight ratios of 1:0.1:0.4:0.4, and then tetrabutyl ammonium tetrafluoroborate $\mathrm{TBABF}_{4}$ is added in a $0.9 \mathrm{M}$ concentration relative to the solution. 30 times cycled scanning at a scan rate of $250 \mathrm{mV} / \mathrm{s}$ from -0.2 to $1.2 \mathrm{~V}$ are enforced to reach $220 \mathrm{~nm}$ thin films. Before examining the optical properties of polymer films, they are rinsed with acetonetrile twice before devices fabrication and then place in a vacuum oven at $80^{\circ}$ centigrade overnight. And followed by spin-coating a gel electrolyte on two separate ITO/ glass substrates, the coated surfaces were manually sandwiched together and sealed with epoxy. The electrochromic devices were placed to dry at room temperature overnight. UV-Vis-NIR spectra are recorded on a V 570 Jasco UV-Vis-NIR spectrophotometer.

The in situ spectroelectrochemistry is performed by holding the film at the desired potential and measuring the absorbance from $400 \mathrm{~nm}$ to $2500 \mathrm{~nm}$ with applied potentials at $0 \mathrm{~V}$ and $2.5 \mathrm{~V}$ vs $\mathrm{Fc} / \mathrm{Fc}^{+}$for p-doping. The polymer switches from a dark teal-green in the neutral state to a slate-blue in the oxidized state. As shown in Figure 2, the polymer EP01 and EP02 have the analogous absorbance bands in the visible region at around $550 \mathrm{~nm}$, characteristic of donor-acceptor systems. A window of transmission is centered on $500 \mathrm{~nm}$ and gives the polymer a green color as the green light is not absorbed and is allowed to pass through the film. As the polymers are oxidized, depletion of both of these transitions occurs with a decrease in the absorbances at 550 $\mathrm{nm}$ and $400 \mathrm{~nm}$. For polymer EP01, the doping-induced 


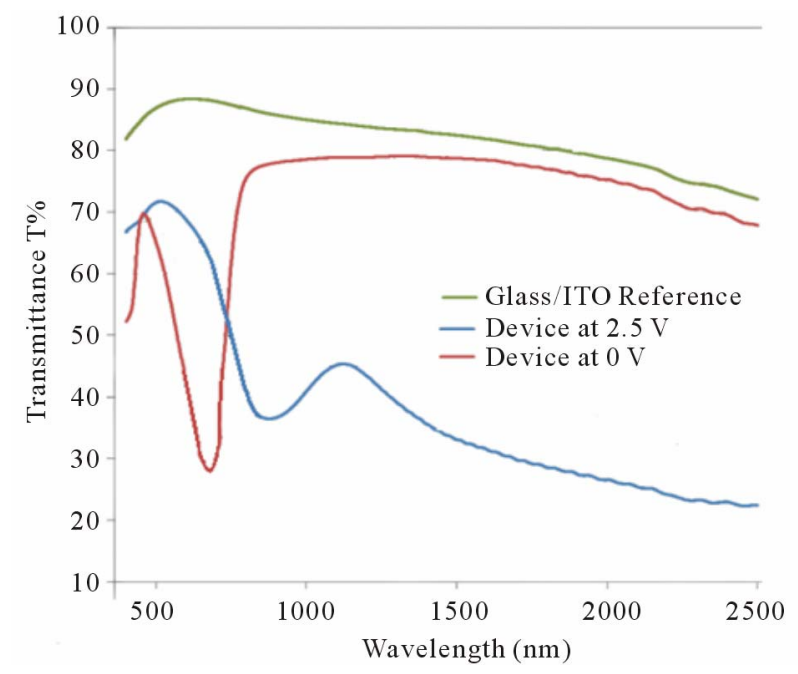

(a)

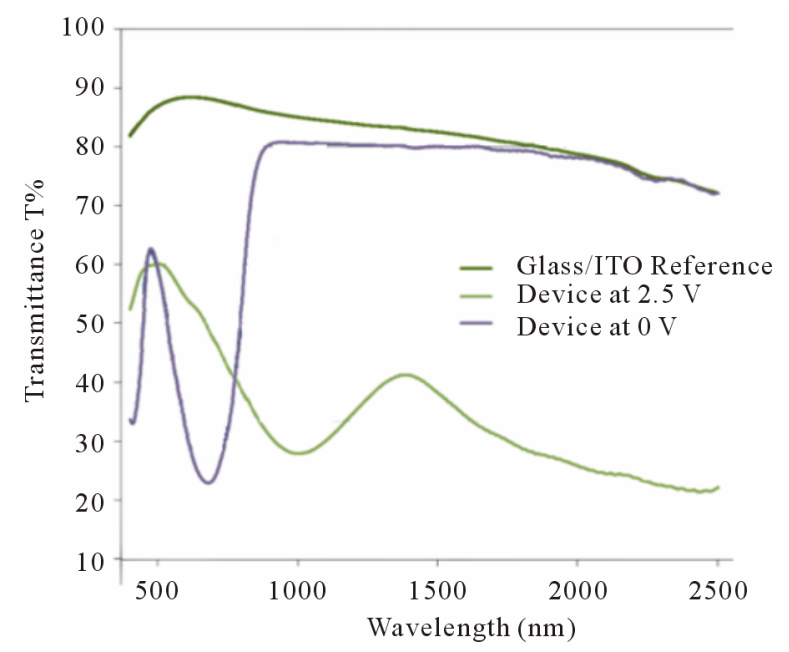

(b)

Figure 2. Electrochromic properties of devices based on (a) EP01 and (b) EP02 at $2.5 \mathrm{~V}$ and $0 \mathrm{~V}$.

infrared absorption bands centered at $900 \mathrm{~nm}$ and a broad absorbance beginning at $1200 \mathrm{~nm}$ and extending into the mid-IR corresponding to $2.5 \mathrm{~V}$ bias. The electrochromic property of EP02 is slightly different when device is turned on. The doping-induced absorbance at around $1000 \mathrm{~nm}$ and a broad absorbance beginning at $1500 \mathrm{~nm}$ and also extending into the mid-IR, which is due to the narrower band gap of origin materials.

While ITO/glass electrodes are sufficiently transparent in the visible region, their transmission window drops off substantially at longer wavelengths, as shown in Figure 2. The ITO/glass utilized in this study has a transmittance value of $85 \%$ at $1500 \mathrm{~nm}$, reduced to $72 \%$ at $2500 \mathrm{~nm}$, the limiting wavelength for solution-based spectraelectrochemistry. In Figure 3, the normalized absorbance of both polymers with the elimination of glass/ITO absorbance revealed that both devices have the maximum con- trast is $85 \%$, almost in the whole mid-IR region have around $80 \%$ contrast. Especially EP02, the absorption curved is more flat and smooth, which meet the practically application requirement well. However, for applying in IR region, an electrode material with higher nearto mid-IR transparency is required in the future.

\subsection{Electrochromic Switching Studies}

Electrochromic switching studies are carried out to monitor absorbance changes with time during repeated potential stepping between reduced and oxidized states to obtain an insight into changes in the optical contrast. In an initial experiment illustrate in Figure 4, the EP01 and EP02 devices are switched by stepping the potential between -2.5 and $+2.5 \mathrm{~V}$ with a switching interval of $10 \mathrm{~s}$ while monitoring the absorbance at $900 \mathrm{~nm}$ and $1000 \mathrm{~nm}$, respectively. The polymer film repeatedly and reproducibly change from a dark blue absorptive reduced state at $-2.5 \mathrm{~V}$ to a light gray transmission oxidized state at $+2.5 \mathrm{~V}$ with a higher transmission. By examination of one of the double potential switches of EP01 and EP02, device based on EP01 need around $4 \mathrm{~s}$ to turn on device to reach $80 \%$ of total transformation and $2 \mathrm{~s}$ to turn device off. Meanwhile, the device based on EP02 switch much faster, which the reduction is completed in $c a .0 .8 \mathrm{~s}$, reoxidation requires around $1.5 \mathrm{~s}$. It can be seen that in both cases the reductive processes proceed somewhat more rapidly than the oxidation processes. The rapidity of the reduction can be attributed to the ease of transport through the polymer film to the electrode contact. Reoxidation of the neutral film initiates at the insulating polymer-electrode interface, and a conducting front propagates through the film's thickness. For EP01, the longer alkyl-substitution on polymer back bone lead to a larger inter-chain distance, which will block the transport from film to electrode. As the result, the conductivity of oxidized polymer EP01 films is lower than that of EP02 and result in a slower turn off speed. Moreover, as the subunit of EP02, the ProDOT (3,4-propylenedioxythiophene), which have cyclic substitutions propylenedioxy, could separate polymer back bone and afford a suitable space for ion injection and accelerate the oxidation process. [31]

\section{Conclusion}

We have prepared two donor-acceptor-donor structured monomers containing extended conjugation systems in good yields which are easily electrochemically polymerized to yield stable and uniform electroactive films. The devices in solid state based on the two polymers show good contrast and rapid responds, which are as high as $80 \%$ in mid-IR region and the switching speed of EP02 is around 1s which is faster than that of EP01. The 


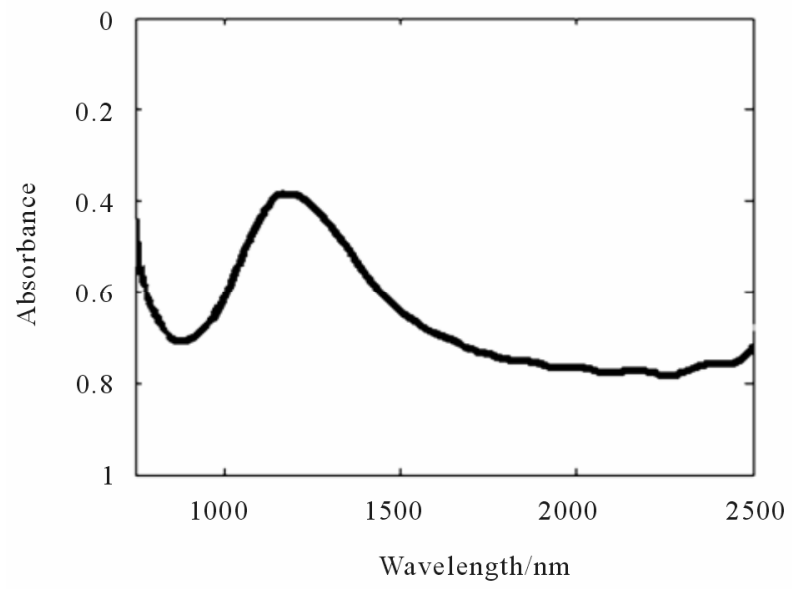

(a)

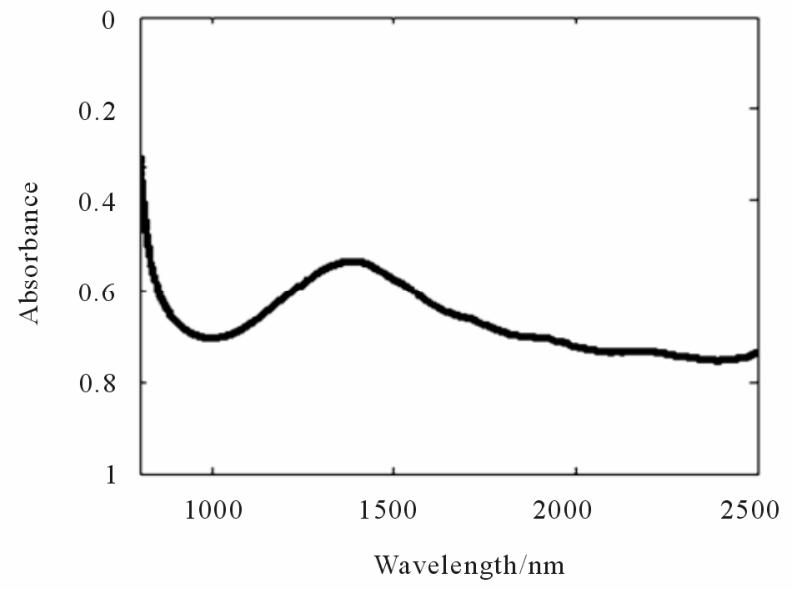

(b)

Figure 3. Normalized devices' contrast in mid-IR; (a) EP01; (b) EP02.

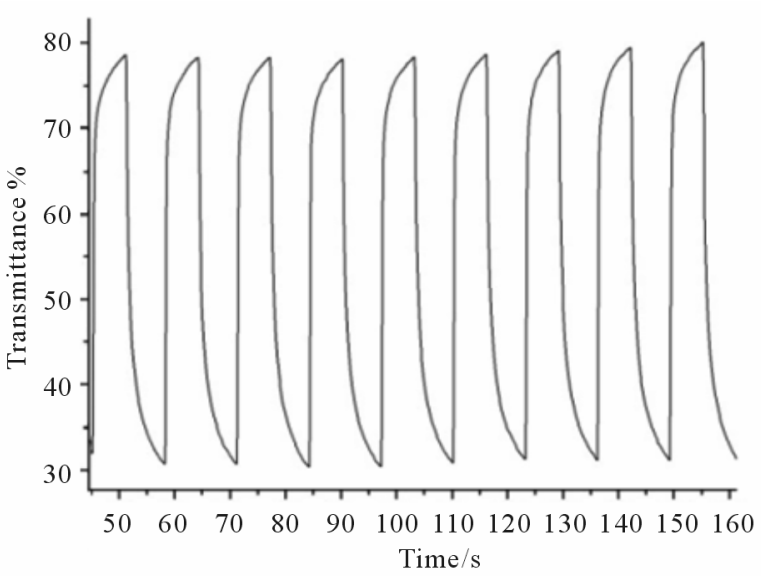

(a)

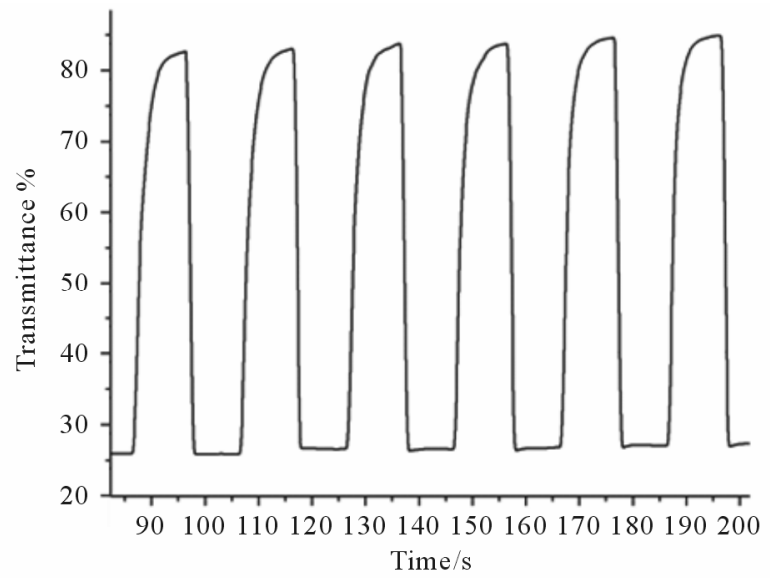

(b)

Figure 4. Switching properties of (a) EP01 and (b) EP02 at $900 \mathrm{~nm}$ and $1000 \mathrm{~nm}$ respectively with $10 \mathrm{~s}$ interval of step bias of $2.5 \mathrm{~V}$ and $-2.5 \mathrm{~V}$.

reason would be the substitutions on EP02 afford suitable size for ion injection, which could accelerate polymer doping. And the side chains on EP02 are shorter than that of EP01, which attributed to reasonable conductivity to ease transport through the polymer film to the electrode. These interesting solubility and easy processability properties open the door to electrochromic applications on large or flexible surfaces such as IR shutters and apertures.

\section{Acknowledgements}

For financial support of this research, we thank the National Natural Science Foundation of China (Grant 21176259), and Chinese Academy of Sciences.

\section{REFERENCES}

[1] P. M. S. Monk, R. J. Mortimer and D. R. Rosseinsky,
"Electrochromism: Fundamentals and Applications," VCH, Weinheim, 1995.

[2] A. Maier and B. Tieke, "Coordinative Layer-by-Layer Assembly of Electrochromic Thin Films Based on Metal Ion Complexes of Terpyridine-Substituted Polyaniline Derivatives," Journal of Physical Chemistry B, Vol. 116, No. 3, 2012, pp. 925-934. doi:10.1021/jp209600d

[3] A. Maier, K. Cheng, J. Savych and B. Tieke, "DoubleElectrochromic Coordination Polymer Network Films," Applied Materials and Interfaces, Vol. 3, No. 7, 2011, pp. 2710-2718. doi:10.1021/am2004976

[4] P. M. Beaujuge and J. R. Reynolds, "Color Control in $\pi$ Conjugated Organic Polymers for Use in Electrochromic Devices," Chemical Review, Vol. 110, No. 1, 2010, pp. 268-320. doi:10.1021/cr900129a

[5] G. Sonmez, "Polymeric Electrochromics," Chemical Communications, Vol. 42, 2005, pp. 5251-5259. doi:10.1039/b510230h

[6] G. Sonmez, H. B. Sonmez, C. K. F. Shen and F. Wudl, "Red, Green, and Blue Colors in Polymeric Electrochro- 
mics," Advanced Materials, Vol. 16, No. 21, 2004, pp. 1905-1908. doi:10.1002/adma.200400546

[7] I. Schwendeman, J. Hewang, D. M. Welsh, D. B. Tanner and J. R. Reynolds, "Combined Visible and Infrared Electrochromism Using Dual Polymer Devices," Advanced Materials, Vol. 13, No. 9, 2001, pp. 634-637. doi:10.1002/1521-4095(200105)13:9<634::AID-ADMA6 $\underline{34>3.0 . C O ; 2-3}$

[8] Y. Xia, J. Luo, X. Deng, X. Li, D. Li, X. Zhu, W. Yang and Y. Cao, "Novel Random Low-Band-Gap FluoreneBased Copolymers for Deep Red/Near Infrared LightEmitting Diodes and Bulk Heterojunction Photovoltaic Cells," Macromolecular Chemistry and Physics, Vol. 207, No. 5, 2006, pp. 511-520. doi:10.1002/macp.200500517

[9] J. Tarver, J. E. Yoo and Y. L. Loo, "Polyaniline Exhibiting Stable and Reversible Switching in the Visible Extending into the Near-IR in Aqueous Media," Chemistry of Materials, Vol. 22, No. 7, 2010, pp. 2333-2340. doi: $10.1021 / \mathrm{cm} 903455 \mathrm{w}$

[10] M. Dietrich, J. Heize, G. Heywang and F. J. Jonas, "Electrochemical and Spectroscopic Characterization of Polyalkylenedioxythiophenes," Journal of Electroanalytical Chemistry, Vol. 369, No. 1-2, 1994, pp. 87-92. doi:10.1016/0022-0728(94)87085-3

[11] L. B. Groenendaal, F. Jonas, D. Freitag, H. Pierlartzik and J. R. Reynolds, "Poly(3,4-ethylenedioxythiophene) and Its Derivatives: Past, Present, and Future," Advanced Materials, Vol. 12, No. 7, 2000, p. 481.

[12] C. A. Thomas and J. R. Reynolds, "Poly(3,4-ethylenedioxypyrrole): Organic Electrochemistry of a Highly Stable Electrochromic Polymer," Macromolecules, Vol. 33, No. 4, 2000, pp. 1132-1133. doi: $10.1021 / \mathrm{ma9916180}$

[13] K. Zong and J. R. Reynolds, “3,4-Alkylenedioxypyrroles: Functionalized Derivatives as Monomers for New Electron-Rich Conducting and Electroactive Polymers," Journal of Organic Chemistry, Vol. 66, No. 21, 2001, pp. 6873-6882. doi:10.1021/jo0016201

[14] B. C. Thompson, P. Schottland, K. Zong and J. R. Reynolds, "In Situ Colorimetric Analysis of Electrochromic Polymers and Devices," Chemistry of Materials, Vol. 12, No. 6, 2000, pp. 1563-1571. doi:10.1021/cm000097o

[15] N. Blouin, A. Michaud, D. Gendron, S. Wakim, E. Blair, R. Neagu-Plesu, M. Belletête, G. Durocher, Y. Tao and M. Leclerc, "Toward a Rational Design of Poly(2,7-Carbazole) Derivatives for Solar Cells," Journal of American Chemical Society, Vol. 130, No. 2, 2008, pp. 732-742. doi:10.1021/ja0771989

[16] M. Helgesen, S. A. Gevorgyan, F. C. Krebs and R. A. Janssen, "Substituted 2,1,3-Benzothiadiazole- and Thiophene-Based Polymers for Solar Cells. Introducing a New Thermocleavable Precursor," Chemistry of Materials, Vol. 21, No. 19, 2009, pp. 4669-4675. doi:10.1021/cm901937d

[17] T. T. Steckler, X. Zhang, J. Hwang, R. Honeyager, S. Ohira, X. Zhang, A. Grant, S. Ellinger, S. A. Odom, D. Sweat, D. B. Tanner, A. G. Rinzler, S. Barlow, J. Brédas,
B. Kippelen, S. R. Marder and J. R. Reynolds, "A SprayProcessable, Low Bandgap, and Ambipolar Donor-Acceptor Conjugated Polymer," Journal of American Chemical Society, Vol. 131, No. 8, 2009, pp. 2824-2826. doi:10.1021/ja809372u

[18] P. Chandrasekhar, G. C. P. Birur, S. Stevens, E. A. Pierson and K. L. Miller, "Far Infrared Electrochromism in Unique Conducting Polymer Systems," Synthetic Metals, Vol. 119, No. 1-3, 2001, pp. 293-294. doi:10.1016/S0379-6779(00)01455-7

[19] P. Chandrasekhar, US Patent 5995 273, 1999.

[20] J. Roncali, P. Blanchard and P. Frère, "3,4-Ethylenedioxythiophene (EDOT) as a Versatile Building Block for Advanced Functional $\pi$-Conjugated Systems," Journal of Materials Chemistry, Vol. 15, No. 16, 2005, pp. 15891610. doi:10.1039/b415481a

[21] P. Chandrasekhar, "Conducting Polymers, Fundamentals and Applications: A Practical Approach," Kluwer, Dordrecht, 1999. doi:10.1007/978-1-4615-5245-1

[22] T. A. Skotheim, R. L. Elsenbaumer and J. R. Reynolds, "Handbook of Conducting Polymers Marcel," Dekker, New York, 1998.

[23] Z. Li, Y. Zhang, A. L. Holt, B. P. Kolasa, J. G. Wehner, A. Hampp, G. C. Bazan, T. Nguyen and E. M. Daniel, "Electrochromic Devices and Thin Film Transistors from a New Family of Ethylenedioxythiophene Based Conjugated Polymers," New Journal of Chemistry, Vol. 35, No. 6, 2011, pp. 1327-1334. doi:10.1039/c0nj00837k

[24] B. Sankaran and J. R. Reynolds, "High-Contrast Electrochromic Polymers from Alkyl-Derivatized Poly(3,4-ethylenedioxythiophenes)," Macromolecules, Vol. 30, No. 9, 1997, pp. 2582-2588. doi: $10.1021 / \mathrm{ma} 961607 \mathrm{w}$

[25] W. L. F. Armarego and C. L. L. Chai, "Purification of Laboratory Chemicals," 5th Edition, Elsevier, Amsterdam, 2003.

[26] C. Zhang, US Patent No. 20040229 925, 2004.

[27] P. H. Kwan and T. M. Swager, "Intramolecular Photoinduced Charge Transfer in Rotaxanes," Journal of American Chemical Society, Vol. 127, No. 16, 2005, pp. 59025909. doi:10.1021/ja042535o

[28] E. M. Galand, J. K. Mwaura, A. A. Argun, K. A. Abboud, T. D. McCarley and J. R. Reynolds, "Spray Processable Hybrid 3,4-Propylenedioxythiophene: Phenylene Electrochromic Polymers," Macromolecules, Vol. 39, No. 21, 2006, pp. 7286-7294. doi:10.1021/ma060466n

[29] A. Durmus, G. E. Gunbas and L. Toppare, "New, Highly Stable Electrochromic Polymers from 3,4-Ethylenedioxythiophene-Bis-Substituted Quinoxalines toward Green Polymeric Materials," Chemistry of Materials, Vol. 19, No. 25, 2007, pp. 6247-6251. doi:10.1021/cm702143c

[30] C. Kitamura, S. Tanaka and Y. Yamashita, "Design of Narrow-Bandgap Polymers. Syntheses and Properties of Monomers and Polymers Containing Aromatic-Donor and o-Quinoid-Acceptor Units," Chemistry of Materials, Vol. 8, No. 2, 1996, pp. 570-578. doi: $10.1021 / \mathrm{cm} 950467 \mathrm{~m}$

[31] B. D. Reeves, C. R. G. Grenier, A. A. Argun, A. Cirpan, 
T. D. McCarley and J. R. Reynolds, "Spray Coatable Electrochromic Dioxythiophene Polymers with High Co- loration Efficiencies," Macromolecules, Vol. 37, No. 20 2004, pp. 7559-7569. doi:10.1021/ma049222y 